\title{
Projection of Women Education and Empowerment Status in Pakistan: A Direct Observation Analysis of Pakistani Dramas
}

\author{
${ }^{a}$ Beenish Ijaz Butt, ${ }^{\text {b Nargis Abbas, }}{ }^{\mathrm{c}}$ Uzma Ashiq, ${ }^{\mathrm{d}}$ Ammara Sarfaraz \\ ${ }^{a}$ Assistant Professor, Department of Social Work, University of Sargodha, Sargodha, Pakistan \\ Email: beenish.ijaz@uos.edu.pk \\ ${ }^{\mathrm{b}}$ Assistant Professor, Department of Education, University of Sargodha, Sargodha, Pakistan \\ Email: nargis.abbas@uos.edu.pk \\ c Lecturer, Department of Social Work, University of Sargodha, Sargodha, Pakistan \\ Email: uzma.ashiq@uos.edu.pk \\ d MPhil Scholar, Department of Social Work, University of Sargodha, Sargodha, Pakistan
}

\begin{tabular}{l}
\hline ARTICLE DETAILS \\
\hline History: \\
Accepted 30 July 2021 \\
Available Online September 2021
\end{tabular}

Keywords:

Women Education, Denzin's Film

Analysis, Women Empowerment,

Policy, PEMRA

JEL Classification:

P36, M54

DOI: $10.47067 /$ real.v4i3.177

\begin{abstract}
The sustainable development goal of gender balanced economic progress and women empowerment as a whole is not possible without the women participation in Science, Technology and Production. To prepare the mind-set of the masses particularly the youth, electronic media plays a pivotal role as a medium of informal education along with entertainment and cultural depiction of a particular society. It shows the status of various population groups of a society at a particular time especially women. The aim of the study was to explore the effects of NPDEW, 2002 on women status in television dramas. Thus, the main research question was to investigate that how far media is projecting its role in educating the individuals about the importance of shrinking the gender gap and developing the networks of skill development to increase the number of women employment and entrepreneurship. This study was qualitative in nature and direct observation analysis was used. Major derived themes from data were women status shown by Pakistani drama channels, portrayal of women status by dramas after promulgation of NPDEW, 2002 and dramas as a mean of information, education and communication. It was concluded that media remained unsuccessful in projecting expected women status in Pakistan as per NPDEW and still unable to educate the masses about the women issues.
\end{abstract}

(C) 2021 The authors. Published by SPCRD Global Publishing. This is an open access article under the Creative Commons AttributionNonCommercial 4.0

Corresponding author's email address: nargis.abbas@uos.edu.pk

\section{Introduction}

Media is not a newly described source of entertainment in the present world. Its images are found in the previous centuries also. Now a days, electronic media as a main source of communication using the mediums of radio and television with provision of entertainment and information (Riaz et al., 2015) influencing the thoughts of people. Media not only presents entertainment but also a source of 
culture depiction of a society. Social scientists have been interested in mass media content since the early 2oth century, starting with Max Weber who saw media content as a means of monitoring the 'cultural temperature' of society (Macnamara, 2005). Media inform as well as they direct the attention of the audience to several topics form several representations of society and allow viewers to experience new situations. In present era, media also builds public opinion. Gender identities, socio cultural norms, political attitudes and even the policies are formed as a result of interplay between media, society and people (Uks, 2009).

Drama is one of the main sources of entertainment and cultural depiction of a particular society. It shows the status of various population groups of a society at a particular time. Drama is used as medium which explores human feeling, social attitudes and social problems. Pakistan television drama is also an important medium which creates higher level of awareness among audience since its beginning (Huma, Z. E. 2015). The Pakistani drama was especially designed to entertain and educate as it was objectively designed for this purpose for addressing social issues, and to create changing attitudes in the society (Singhal, \& Rogers, 1999). Two decades before, only PTV was a main source of drama entertainment from provincial capitals of Pakistan. Now a day, there are a number of private channels licensed by PEMRA (Pakistan Electronic Media Regulatory Authority) like ARY Digital, HUM TV and Geo TV displaying social structure and status of women in the society.

The drama serials of today are mostly concerned with the premarital and post-marital situations and conditions of both domestic and working women of Pakistan. On air dramas from Pakistani channels depict a variety of roles of women representing their societal conditions and status in the society. Women of these dramas are mostly subjected to some form of violence and hardships (Huda, \& Ali, 2015). Others are seen as enjoying the high-class facilities in their lives with the portrayal of elite class life style. There is a diversity of women roles presented by dramas in Pakistan.

On the other hand, women status in society Pakistan is one of the countries of South Asia, having a high ratio of gender inequality. The HDI, in terms of the "Gender Inequality Index (GII), reflects gender-based inequalities in three dimensions- reproductive health, empowerment, and economic activity. Pakistan has the GII value of 0.567 , ranking it 123 out of 148 countries on the globe" (UNDP, 2013). This shows a high percentage of gender disparities in education, health, employment, decision making and family status in Pakistan. Contrary to this, to remove gender disparities from Pakistani society, Government of Pakistan had introduced Pakistan's National Policy for Development and Empowerment of Women (NPDEW) in 2002 which aimed at removing gender inequities and imbalances in all sectors of life. The said policy addresses the education, health, law and access to justice, violence against women, women in family and community, the girl child, economic empowerment, poverty access to credit, remunerated work, political empowerment and role of media for women in Pakistan.

Regarding the role of media, the said policy addresses,

"Enhancing the role of media as a mean of information, education and communication on women's issues and for a positive portrayal of women in all media” (GOP, 2002.)

Government has promulgated to present a positive portrayal of women status in the society in 2002 and to educate and communicate women issues to the society but still gender disparities are at high rank in Pakistan. This instigates research questions that what type of women status was shown by Pakistani drama channels? Do drama channels portray the women status as stated by the policy? Do 
the social issues of these dramas are educating the citizens or vice versa? Do these dramas are helpful in minimizing gender inequality? Do these dramas are challenging traditional women roles in Pakistan society? To answer these research questions, the present study explained and explored the effectiveness of women. The purpose of present research is to investigate the dramas broadcasted by Pakistani media for the portrayal of women.

\section{Literature Review}

The way women are represented in the media does have an influence on how we perceive women roles. The trends of women projection in international media can't be considered as ideal. In current TV programs generally, typical female representations are followed for women portrayal. Women are expected as beauty tool to fascinate viewers. In Pakistani media women portrayal is not only positive but the women roles in TV dramas are mostly presented with a negative impact. The continuity of negative portrayal and representation of women may be linked to the lack of national media codes and their execution (Uks, 2009). Such implications limit the improvement of the overall women's images. In some drama serials women are still portrayed as being subordinate while in information-based topics, functions, etc. women are projected to be underrepresented (Luif, 2014).

While searching for the literature it was observed that the old dramas were significant in their portrayal of feminine strength but in current dramas, the portrayal of women is negative and is shown as weak victims (Jiwani, 2013). They are only manipulated for unfair illustration (Simorgh, 2003) and are being used as a commercial asset (Zulfiqar, \& Babary, 2011). According to a report of media and gender in Pakistan, it is observed that the depiction of women role still remains stereotypical and patriarchal and sometimes they are being violated also (IFJ, 2015). These stereotypical images convey the concept of domestic violence and mostly men are represented as aggressors (Bimbi, 2011). The way women are treated and portrayed in this field exposes women to sexual harassment (Huda, \& Ali, 2015).

Television dramas need a change of direction that portray women in different roles and represent women issues (Ibrahim et al., 2017). It is the need of hour to change the presentation of women portrayal in Pakistani television dramas (Huma Z. E, 2015). Television dramas should be more informative, future oriented, educational, inspiring and rational as stated in the policy that could improve the status of women. Positive women projection on media will be equally beneficial to both women and society as well. Therefore, the aim of the study was to explore the effects of NPDEW, 2002 on women status in television dramas. Thus, the main research question was to investigate that how far television dramas is projecting its role in educating the individuals about the importance of shrinking the gender gap and developing the networks of skill development to increase the number of women employment and entrepreneurship.

\section{Research Methodology}

The purpose of this research is to find out the effectiveness of women empowerment policy for women portrayal through HUM TV Dramas. To explain the said issue, this study was conducted by using qualitative research method and used direct observation. To draw a sample for direct observation, the PEMRA (Pakistan Electronic Media Regulatory Authority) licensed drama channels were listed. HUM TV drama channel was selected and its prime-time dramas displayed at 8-9 pm (from Monday to Sunday) were selected by using purposive sampling technique. The On-Air dramas of prime-time HUM TV (started from 2018 to 2019) were selected and were recorded for the research proceedings. The observation involved watching each of the episodes of above said dramas. The data files were collected by recording all the episodes of each drama separately. The data was analyzed by following the overall process guided by Denzin (2004) using Denzin's Film Analysis. Denzin's realistic reading approach was 
adopted which focuses the understanding of a film/drama as a truthful description of a phenomenon, whose meaning can be completely disclosed through a detailed analysis of the contents and the formal features of the images. The interpretation serves to validate the truth claims that the film makes about the reality (Flick, 2014).

\section{Analysis \& Discussion}

After watching all the dramas carefully and accordingly, direct observation analysis is applied on the driven patterns.

\subsection{Women Status Projected By Pakistani Drama Channels}

With the revolution of technology and multimedia industry massive changes are brought in every field of life including showbiz and drama industry. Drama industry of a country presents its cultural norms and values along with prevailing issues in the society. In similar manner, entertainment industry of Pakistan is expanding day by day through presentation of several emerging issues and trends in the society. Thus, it's being influential in pavement of life style of masses through dramas, movies, morning shows and other routine entertainment shows.

In HUM TV dramas women are portrayed both in negative and positive roles but most of the times negative role is more focused. Moreover, women are also projected as rude and immoral being not able to give or take respect. Such a negative portrayal of women affects the audience negatively. In this way, it seems like when a woman is shown as playing negative role, she actually affects the mind set of all society and leaves an image on the minds of audience. Exploring it further, another discussant shared that while presentation of women character in dramas through the concept of women empowerment, cultural values of the society is entirely ignored. In this way, it went far away from the reality and unable to leave positive impact on the society.

It is also observed that when there is a positive character, it is a poor and underprivileged character, as it is oppressed in society, disadvantaged and being violated. It is positive because the character is displayed as bearing each and everything in every situation but if the character is negative, it is shown as the privileged one. It seems that positivity is usually attached with vulnerability or victimization. Such victimized characters are portrayed to induce the feelings of sympathy because they bear each and everything without any complaint. On the other hand, those who are negative they are benefited somehow. In this way, sometime incomplete or partial presentation of a character could misguide the audience. For instance, a person watches in dramas that how the culprits who violates women in any manner, escaped the law or not punished. It could motivate him towards negativity as he observed that there is no harm in it for him. In such cases it is necessary to create the situation in such manners that people get some positive lesson through it instead of negativity. From his views, it could be like when all the time, close relatives are presented as cruel or having ill treatment with women in the family, while secondary relationships are being very supportive in dramas, such situation could weaken the family system or internal ties among the family members. Bearing in mind that parent, siblings or spouse could not be supportive in achieving a particular purpose, a person could get away from these relations.

Women characters are not always displayed in stereotypical manners but it is tried to show reality-based balance picture of both negative and positive women characters in dramas. in dramas women are only shown as problem facer at domestic level in the role of being a mother, mother-in-law, sister, daughter in law etc., whereas there are only a few dramas shown the problem of working 
women. So, it could be said that audience needs change in the subject matter of typical drama stories and replace with new changing trends.

\subsection{Portrayal of women status by dramas after promulgation of NPDEW, 2002}

Social and cultural changes are natural social phenomenon occurring with passage of time. The decade of 90's portrayed women status quite differently in TV dramas. At the start of the $21^{\text {st }}$ century, with the promulgation of NPDEW, 2002, the dramas took a new form in Pakistan. There were multiple private channels but bound under PEMRA to follow the said policy. The portrayal of women before policy was quite simple with no luxury exhibitions, but after the promulgation of policy it presents some new version of family culture, women status and contemporary social problems.

Firstly, after adopting new policy the Pakistani dramas were much glamorous as ever before. The material and non-material culture presented in dramas is of a new version. The women with attractive dressing and jewelry and make up, no doubt, look attractive but it created a discriminatory atmosphere in the family culture. After watching dramas women naturally are attracted to this material culture while the family's economic condition is still poor in Pakistan. This creates a cultural lag in the society.

Family culture in Pakistan is still dependent on the economic status of the families. Dramas show that women of rich families are more empowered than the poor ones and poor are always the sufferers. This presents an image for the society and earning more money is the only solution of all the problems a poor person has. The contemporary issues discussed by the dramas either revolve around the family politics and marital affairs.

Women status portrayed in family politics is of such a version that Pakistani women just perform this role in the society and their domestic chores are second priority. While in reality it looks like a morphed version of family atmosphere in Pakistan. Secondly, love affairs including pre-marital and post marital affairs are so commonly presented that it seems like it is a normal routine of our culture but it is not so common in society. So, the portrayal of women after NPDEW, 2002, has changed. Women are shown empowered in terms of taking decisions in the family but on actual grounds, it is not the reality of our society.

As seen before, portrayal of women's characters in Pakistani dramas reinforce many stereotypical ideologies about them. This concept shows how the Pakistani drama channels and Pakistani plays enforce traditional beliefs and ideologies regarding women, which they must strive to challenge or change. As it is seen in the Pakistani society, women are often portrayed to be inferior to men in many comic and serious ways. Even when Pakistani plays and Pakistani drama channels intend to raise serious issues regarding women, and make bold statements, the portrayal of women in the dramas always make it in a manner which enforces negative beliefs and ideologies about them. For example, the character of Raani, in Alif Allah aur Insaan, is portrayed to be forced by her father to wander the streets for begging as a source of income. This should make Raani very aware about the world around her, very smart and strong. However, Raani is still shown to be clueless about how cruel the world can be and she chooses the wrong path to get rid of her problems and the success also.

Such actions represent women in a negative way. It reinforces the aspects of innocence childishness and naiveté about female characters, which is much fictionalized and would not be in the real world. Such as in Yeh Raha Dil, the character of hayat is portrayed in the same way. But in reality, such characters are only few in millions. So, there is no such positive change can be observed after the 
promulgation of the NPDEW, 2002 and women are still presented in a strange manner in the dramas. This is a highly alarming phenomenon for women in Pakistan, as the main audience for the Pakistani plays and Pakistani drama channels is also intended to be that of females. The drama industry must strive towards creating a social change with the help of the platforms that they have and present the females as stated in the policy.

\subsection{Dramas as a Mean of Information, Education and Communication}

Pakistani dramas after promulgation of NPDEW, 2002 were supposed to be a mean of information, education, and communication about women's issues. The contemporary social issues of women in Pakistan revolve around poverty, violence, illiteracy exclusion in decision making body of family, mobility issues and dependence in case of seeking permission for certain acts.

As far as the information, communication and education provided by the drama is concerned they are promoting fashion industry of the country as a first impression. Other than the material culture the women issues are communicated in the way as they can make it more attractive to attract the attention of the viewer's rather than to educate an issue.

As in certain dramas polygamy is shown as common as it is a privilege in most of the families (as in drama DIL-E-JANAM) but in reality it's not still common. Where there is polygamy without the family consent, there is a huge problem which is not shown by these dramas. Further dramas have not shown that when someone acts so, there is a legal punishment for that as promulgated as Muslim family law ordinance, 1961. But dramas just presented the polygamy as an interesting story but do not educate serious harms and allegations associated with this.

Poverty among women is still an alarming issue after the seven decades of creation of Pakistan but dramas have presented the issue in a negative way (as in ALIF ALLAH AUR INSAN). If a woman is poor she can be a beggar or a prostitute. The dramas have not educated the different govt. (like BISP, DARULFALAH) and non govt. schemes and institutions where omen can get social assistance. It is also shown by the dramas that in rural areas the policies are related to women empowerment have no influence.

The policies are not properly promulgated due to cultural constraints. The local political conducts are not interested in enhancing the cultural of their community so the law and order is still show weak and hence, women of poor families are shower in a miserable condition.

Many of the Pakistani plays and drama channels do not deliver any education, but rather they create unhealthy, patriarchal belief systems and ideologies about women roles in the Pakistani society. It is of utmost importance for Pakistani plays to deliver some sort of education for the general public, and educate them on the contemporary issues of the Pakistani society. Instead, the drama industry only make stories that audience like to watch. However, this is not true for all Pakistani plays and all Pakistani drama channels. Many of the Pakistani plays and drama channels do intend to educate the general public by raising awareness about certain issues of the Pakistani society, and the issues that are persistent within it. However, even when a play or a drama channel does that, they do it in a manner that reinforces traditional women roles.

This phenomenon is a highly negative issue and an alarming fact for the women in the Pakistani society, as their issues, gender roles, and gender norms are needed to be broken instead of being revitalized. Such issues are needed to pay attention in the Pakistani society, and the drama industry 
needs to strive for educating the general public about the mundane, day-to-day issues and their solutions or at least how to cope with them that women have to face in the Pakistani society. While many Pakistani plays does do that, they do not enforce a positive character for females in the Pakistani society. They intend to show the vulnerability and helplessness of the feminine aspect in their TV dramas; however, they end up conforming to the beliefs that are stereotypical and traditional, rather in a positive manner. The same patterns are spun again and again in most of the Pakistani plays and by most of the Pakistani drama channels. These patterns are needed to be broken in order to create a change in the society of Pakistan, which can only be possible through educating the general public. The unawareness and the ignorance of the Pakistani society is what is needed to be broken down and changed by the Pakistani plays as it has such a large audience, however, such aspects are the ones that the Pakistani plays and the Pakistani drama industry strive towards reinforcing in order not to offend any aspect of the Pakistani society, the Pakistani tradition or the Pakistani culture.

\section{Conclusion \& Suggestion}

Social policies are rendered to provide welfare to the oppressed group of a society. Women undoubtedly are still an oppressed group in our society. To uplift their status in the society, the government of Pakistan presented national policy for development and empowerment of women 2002 in Pakistan. For the media it was promulgated to present a positive image and educate the masses about women roles in the society. It is very important to know the political environment under a promulgated policy. The said policy was implemented in the era of an army ruler in Pakistan following the liberal policies in different domains also. Under this liberal umbrella, the media on one hand presented the liberal role of women in private Pakistani dramas by modernizing their way of living, dressing and mobility in the society. But modernizing material culture does not mean that the media has presented their empowered role. On the other hand, issue of gender inequality, violence, poverty, prostitution, polygamy is presented which is description of women issues. The society is well aware of the social issues. But the question is still unsolved that how/when they will uplift women status.

Media is failed in describing the policies related to women status in Pakistan. It is unable to present a definite solution for the issues like violence and amendment of certain policies which are unable to uplift women status. On the other side of picture as media affects minds of the regular viewers and may result in an acceptance of roles presented by TV plays, no matter they are presenting women as submissive or they have to fight within the domestic domain by hook and crook.

Another point of discussion is that government wants to change values of the society by "spin doctoring" in which the state actors spin in a different way on a story so that the values of the state workers/politicians become the same for the citizens but actual problem is on its original place. Govt. wants to bring people to such values that people accept women in "modern get up with old status quo". There has been always a tug of war between different liberal and conservative governments in Pakistan regarding women status. There is a conflict between these two ideologies and each one is unsuccessful to develop a nexus to elevate women status in Pakistan. Thus, it is suggested that status of women in the society through the role of media as a mean of information, education and communication can be improved. A positive portrayal of women status in the society the government might carry out the effective evaluation of the women promulgated policies in the country and on the basis of it should be amended for the provision of women welfare in the country. 


\section{References}

Denzin N. and Lincoln Y. (2000). Handbook of qualitative research. London: Sage Publication Inc.

Flick, U. (2009). An introduction to qualitative research (4th Ed.). London: Sage Publications Limited.

Huda, A. R. U., \& Ali, R. A. (2015). Portrayal of women in Pakistani media. International Journal of Academic Research and Reflection. 3(1).

Huma, Z. E. (2015). Analytical study of television drama narratives. Journal of Mass Communication Journalism, 5(8).

Ibrahim, F., Yunus, N., Ilias, M., \& Mokhtar, A. H. A. (2017). Portrayal of Women's Images in Television Dramas: A Malaysian Case. SHS Web of Conferences (Vol. 33). EDP Sciences.

Ingham, H. (1995). The portrayal of women on Television. Lawrence Erlbaum Associates: Mahwah, NJ, Retrieved from http://www.aber.ac.uk/media/Students/hzig401.html

Jiwani, M. (2013). A Look at the Shift in Female Characters in Television Dramas from Strong Survivors to Meek Victims (in light of Tanhayian and Humsafar). (Master's thesis). retrieved fromhttp://indusvalley.edu.pk/library1/2013/Communication\%20Design/Mahak\%20Jiwani/Mahak\%20Jiwa ni\%20Dissertation.pdf

Macnamara, J. (2005). Media content analysis: its uses, benefits and best practice methodology. Asia Pacific Public Relations Journal, 6(1).

Riaz, F., Mehmood, S., Abbas, Z., Alamzaib, M., \& Hameed, S. (2015). A comparative study of PTV Home and GEO entertainment channels in Rawalpindi and Islamabad. The Explorer Islamabad: Journal of Social Sciences, 1(7).

Singhal, A., \& E. Rogers. (1999). Entertainment education: a communication strategy for social change. New Jersey: Lawrence Erlbaum Associates.

Uks, R. C. (2009). More women in media. Islamabad: Uks publications.

Unite Nations Development Programme. (2013). Human development report 2013: the rise of the south: human progress in a diverse world. New York: UNDP.

Zulfiqar, F., \& Babary, A. (2011). Historical analysis of representation of media women. The Explorer Islamabad: Journal of Social Sciences, 1(1). 